\title{
Study of Marital Adjustment and Sexual Behaviour \\ In Correlation With Quality of Life in Patients \\ With Schizophrenia and Bipolar Disorder
}

Priyanka Rai', Preeti Mishra', Shobit Garg, Jyoti Mishra', Sayeed Akhtar

\begin{abstract}
:
Background: Marriage is a social process requiring certain social ability for it to be successful. Schizophrenia can lead to a reduction of social ability which has been associated with poor marital adjustment and sexual satisfaction among partners. The present study was designed to compare marital adjustment and sexual behaviour in correlation with quality of life in patients with schizophrenia and bipolar disorder. Method: Study group consisted of outpatients with schizophrenia $(n=30)$ and bipolar disorder $(n=30)$ diagnosed according to ICD 10-DCR. Garos Sexual Behaviour Inventory (GSBI), Marital Adjustment Scale (MAS) and WHO Quality of Life (WHO QoL)-BREF were applied in both the groups to assess sexual behaviour, marital adjustment and quality of life, respectively. Results: Both groups reported that they had problems in marital adjustment and sexual behaviour. Patients with schizophrenia had significantly greater problems in marital adjustment and sexual behaviour. Patients with schizophrenia had statistically significant lower scores in different areas of GBSI. Quality of life in bipolar patients was negatively correlated with confidence domain of GSBI. Conclusion: Patients with bipolar and schizophrenia had problems in marital and sexual life. It was also found that schizophrenic patients had greater problems in the adjustment with their spouses.
\end{abstract}

Key words: Schizophrenia, bipolar disorder, marital djustment, sexual behaviour

\section{INTRODUCTION:}

Marital adjustment, defined as the "state in which there is an overall feeling in husband and wife of happiness and satisfaction with their marriage and with each other (Thomas, 1997). But living with a spouse who has been diagnosed with psychiatric illness or who develops psychiatric illness during the marriage places an enormous strain on all aspects of the relationship. Consequently spouse's marriage and sexual life are disturbed. In recent years, numbers of studies examining the presence of various mental illnesses and their effect on marital adjustment and sexual behaviour have been conducted. Not surprisingly, researchers are finding significant correlations between mental illness and distress in couple relationships in various domains of marital adjustment, sexual behaviour and quality of life (Hickey et al, 2005; Jackman-Cram et al, 2006). Thara (1997) found poor outcome of marriage in schizophrenia. With spouse having bipolar disorder experiencing mood swings and symptoms of mania or depression at any given time, it can present a tough challenge for both the husband and wife in their relationship. This may lead to an unhealthy and disorganized relationship. Studies examining how bipolar disorder influences outcome in marriage are limited. In the Stony Brook High-Risk Project, patients of major depression, bipolar disorder and schizophrenia with a normal control sample were included in a longitudinal study. Marital Adjustment Test (MAT; Locke \& Wallace, 1959) scores were collected on patients at entry into the project (Phase I) and at three year follow-up (Phase II). Course of marriage was defined as negative if the couple's marital adjustment was rated as poor at Phase II or resulted in divorce or separation at Phase II. It was found that all three patient groups had significantly higher rates of divorce by Phase II (Weintraub \& Neale, 1984; Beach, 1986).

Psychiatric patients rarely speak of their sexual life spontaneously. Although limited data is available on sexuality in persons with schizophrenia, a few studies have been published in the past decade. Generally, patients with schizophrenia are far less active sexually than the rest of the population and get less satisfaction. Just as he gives up in other areas he eventually abdicates his sexual role, withdrawing from temptations that seem to promise torment (Shulman, 1971). Research shows that men and women with schizophrenia are still interested in sexual relations but do not know how to bring their feelings into conscious (Jacobs \& Bobek, 2009).

An effort made by Raja \& Azzoni (2003) investigated sexual behaviour in a population of psychiatric patients affected by schizophrenia, schizoaffective disorder and bipolar disorder by means of an ad hoc questionnaire designed to explore three phases of sexual responses: 
desire (or interest), arousal, and performance. Schizophrenia and female gender were associated with lower levels of sexual performance. Mazza et al (2010) studied sexuality and sexual behaviour in women with bipolar disorder. They found increase in sexual interest in Bipolar Disorder I as compared with Bipolar Disorder II female patients and normal controls.

It was very apparent question that if already lots of studies have been done on marital and sexual life of patients with schizophrenia and bipolar disorder so what is the need for conducting this present study. The present study was designed not only to see marital and sexual life of patients with bipolar and schizophrenia disorder but also to make an effort to see the effect on their quality of life.

\section{MATERIALAND METHOD:}

The participants were informed about the intent of the study and after obtained consent they were included in the study. None of the participants were paid for their participation. The total sample size consisted of 60 participants out of whom 30 were patients with diagnosis of schizophrenia $(n=30)$ and another 30 were patients with a diagnosis of bipolar disorder $(n=30)$ according to ICD10-DCR with no history of head injury or any neurological disorder atleast eight years of formal education. Those patients were also excluded who had personality and substance use disorder or any other major psychiatric illness. The age range for both groups was 18 to 60 years. The sample was collected from the outpatient department of Central Institute of Psychiatry, Ranchi for a period of two months. The following rating scales were applied on the participants after obtaining information on a specially designed socio-demographic and clinical data sheet.

Garos Sexual Behaviour Inventory (GSBI; Garos et al, 2007) was used which is a self report format consisting of 70 items that describe a variety of sexual attitudes and behaviours. Response were given on a scale ranging from 1 (Strongly disagree) to 5 (Strongly Agree). Thirty five items comprise four main scales: Discordance (DISC), sexual obsession (SOBS), Permissiveness (PERM), and sexual stimulation (STIM). Twenty five items make up the three masking scales: Sexual control difficulties (CONDIF), sexual excitability (EXCIT), and sexual inventory (INSEC). The remaining 10 items served as masking items. Test-retest reliability estimate for GSBI scores range from .70 to .93 (median=.84).

Marital Adjustment Scale (MAS; Locke \& Wallace, 1959) was used to measure marital adjustment. This consists of a 15 item questionnaire that assesses the respondent's level of happiness with marriage partner and relationship. Response were given on a scale ranging from 6 (Always agree) to 1 (Always Disagree). Possible scores on MAS were 0 to 158 . The higher score was indicative of greater adjustment. The MAS distinguished between martially distressed and martially adjusted relationship with a score of 101 or lower found to identify distressed marital relationship (Cross \& Sharpley, 1981; Locke \& Wallace, 1959).

The World Health Organization, Quality of Life-BREF (WHOQOL-BREF, 1996) comprised of 26 items. This is a shorter version of the original instrument, WHO-QOL100. All items were rated on a 5-point Likert scale. The raw scores were transformed into 0-100 scale and higher scores denote better quality of life. The internal consistency of the four domains of the WHOQOL-BREF ranged from 0.66 to 0.80 .

\section{RESULTS:}

In socio-demographic variables (Table 1) no significant difference was found in any of the socio-demographic domains in both schizophrenia and bipolar disorder group.

Table 1: Comparison Of socio-demographic variables between patients of schizophrenia \& Bipolar Disorder $(\mathrm{N}=60)$

\begin{tabular}{|c|c|c|c|c|c|c|}
\hline Variable & & $\begin{array}{l}\text { Bipolar Patients } \\
n=30(\%)\end{array}$ & $\begin{array}{l}\text { Schizophrenia Patients } \\
n=30(\%)\end{array}$ & $x^{2}$ & df & $\mathrm{p}$ \\
\hline Sex & $\begin{array}{l}\text { Female } \\
\text { Male }\end{array}$ & $\begin{array}{l}7(23.3) \\
23(76.7)\end{array}$ & $\begin{array}{l}5(16.7) \\
25(83.3)\end{array}$ & .417 & 1 & .748 \\
\hline Religion & $\begin{array}{l}\text { Hindu } \\
\text { Muslim } \\
\text { Christian }\end{array}$ & $\begin{array}{l}24(80) \\
4(13.3) \\
2(6.7)\end{array}$ & $\begin{array}{l}23(76.7) \\
5(16.7) \\
2(6.7)\end{array}$ & .132 & 2 & 1.00 \\
\hline Occupation & $\begin{array}{l}\text { Employed } \\
\text { Unemployed }\end{array}$ & $\begin{array}{l}21(70) \\
9(30) 14(46.7)\end{array}$ & 16(53.3) & 1.76 & 1 & .288 \\
\hline Habitat & $\begin{array}{l}\text { Rural } \\
\text { Urban }\end{array}$ & $\begin{array}{l}11(36.7) \\
19(63.3)\end{array}$ & $\begin{array}{l}19(63.3) \\
11(36.7)\end{array}$ & 4.267 & 1 & .070 \\
\hline Education & $\begin{array}{l}\text { Illiterate } \\
\text { Literate }\end{array}$ & $\begin{array}{l}6(20) \\
24(80)\end{array}$ & $\begin{array}{l}8(26.7) \\
22(73.3)\end{array}$ & .373 & 1 & .761 \\
\hline $\begin{array}{l}\text { Socioeconomic } \\
\text { status }\end{array}$ & $\begin{array}{l}\text { LSES } \\
\text { MSES } \\
\text { HSES }\end{array}$ & $\begin{array}{l}8(26.7) \\
20(66.7) \\
2(6.6)\end{array}$ & $\begin{array}{l}11(36.7) \\
15(63.3) \\
4(32.0)\end{array}$ & .693 & 1 & .580 \\
\hline $\begin{array}{l}\text { Embarrassing } \\
\text { Behaviour }\end{array}$ & $\begin{array}{l}\text { Absent } \\
\text { Present }\end{array}$ & $\begin{array}{l}21(70) \\
9(30)\end{array}$ & $\begin{array}{l}17(56.7) \\
13(43.3)\end{array}$ & 1.148 & 1 & .422 \\
\hline
\end{tabular}

$\mathrm{P}=\mathrm{NS}$

Eastern J. Psychiatry Vol. 14, No. 1-2 
Table 2 shows comparison of scores in different areas of GSBI, MAS and WHOQOL- BRIEF in two groups.

Table 2: Intergroup comparison on Garos Sexual Behavior Inventory, Marital Adjustment Scale and WHOQOL scores

\begin{tabular}{|c|c|c|c|c|}
\hline Variable & $\begin{array}{l}\text { Bipolar Patients } \\
(n=30) \\
\text { MeantSD }\end{array}$ & $\begin{array}{l}\text { Schizophrenia Patients } \\
(n=30) \\
\text { Mean } \pm \text { SD }\end{array}$ & $t(d f=58)$ & $\mathbf{P}$ \\
\hline WHOQOL & $39.86 \pm 8.335$ & $35.40 \pm 10.572$ & 1.796 & .078 \\
\hline GSBIDISC & $20.60 \pm 4.85$ & $41.30 \pm 9.524$ & 10.607 & $.001^{* * *}$ \\
\hline GSBIPERM & $43.80 \pm 9.62$ & $24.03 \pm 2.89$ & 10.968 & $.001^{* * *}$ \\
\hline GSBISTIM & $24.0 \pm 2.841$ & $11.40 \pm 1.92$ & 20.120 & $.001^{* * *}$ \\
\hline GSBISOBS & $37.0 \pm 7.97$ & $15.30 \pm 5.093$ & 12.57 & $.001^{* * *}$ \\
\hline GSBICONDIF & $35.10 \pm 6.34$ & $33.87 \pm 6.296$ & .756 & .453 \\
\hline GSBIEXCIT & $41.50 \pm 5.75$ & $22.33 \pm 4.95$ & 13.83 & $.001^{* * *}$ \\
\hline GSBIINSEC & $33.77 \pm 5.98$ & $13.63 \pm 4.15$ & 15.161 & $.001^{* * *}$ \\
\hline MAS & $32.77 \pm 9.84$ & $27.27 \pm 8.12$ & -2.63 & $.022^{* *}$ \\
\hline
\end{tabular}

**p is significant at $<0.01$

$* * *$ p is significant at $<\mathbf{0 . 0 0 1}$

Mean age of the sample population was $39.18( \pm 5.88)$ years. There was significant difference between bipolar and schizophrenia patients with respect to scores of MAS and different areas of GSBI. It was found that scores of MAS $(t=2.63 p<0.01)$ were significantly higher in patients with bipolar disorder $(32.77 \pm 9.84)$ as compared to the schizophrenia (27.27 \pm 8.12 ). The scores of GSBI-DISC

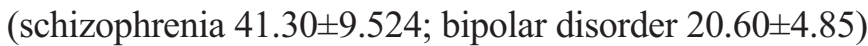
$(\mathrm{p}<0.001)$, GSBI-PERM (schizophrenia 24.03 \pm 2.89 ; bipolar patients $43.80 \pm 9.62)(\mathrm{p}<0.001)$, GSBI-STIM (schizophrenia 11.40 \pm 1.92 ; bipolar disorder 24 \pm 2.841 ) $(\mathrm{p}<0.001)$, GSBI-SOBS (schizophrenia 15.30 \pm 5.093 ; bipolar disorder $37 \pm 7.97)(\mathrm{p}<0.001)$, GSBI-EXCIT (schizophrenia 22.33 \pm 4.95 ; bipolar disorder 41.50 \pm 5.75 ) $(\mathrm{p}<0.001)$ and GSBI-INSEC (schizophrenia 13.63 \pm 4.15 ; bipolar disorder $33.77 \pm 5.98)(\mathrm{p}<0.001)$ are also significantly lower in patients of schizophrenia as compared to patients of bipolar disorder. Table 3 a shows correlation between scores of different areas of GSBI and MAS with scores of WHOQOL-BREF and embarrassing behaviour in schizophrenia patients $(\mathrm{N}=30)$.

Table 3a: Correlation (r) between Garos Sexual Behavior Inventory and Marital Adjustment Scale with Embarrassing behavior and WHOQOL in schizophrenia

\begin{tabular}{|l|l|l|l|l|l|l|l|l|}
\hline Variable & GSBI & $\begin{array}{l}\text { GSBI } \\
\text { DISC }\end{array}$ & $\begin{array}{l}\text { GSBI } \\
\text { PERM }\end{array}$ & $\begin{array}{l}\text { GSBI } \\
\text { STIM }\end{array}$ & $\begin{array}{l}\text { GSBI } \\
\text { SOBS }\end{array}$ & $\begin{array}{l}\text { GSBI } \\
\text { CONDIF }\end{array}$ & $\begin{array}{l}\text { GSB } \\
\text { EXCIT }\end{array}$ & MASSC \\
\hline WHO-QOLBREF & -.288 & -.179 & -.051 & .026 & .129 & .076 & -.005 & .161 \\
\hline Embarrass behaviour & -.020 & .108 & -.095 & .018 & $-.095^{*}$ & .038 & .152 & -.053 \\
\hline
\end{tabular}

The domain of GSBI-CONDIF has statistically significant negative correlationwith embarrassing behaviour $(\mathrm{r}=-0.42)$. Table $3 \mathrm{~b}$ indicates that education was negatively correlated with GSBISTIM(r=0.507). Negative correlation was also found in economic status with GSBI-STIM $(\mathrm{r}=-0.405)$. QOL was negatively correlated with GSBI-CONDIF ( $\mathrm{r}=-$ $0.2 .40)$.

Table 3b: Correlation (r) between Garos Sexual Behaviour Inventory and Marital Adjustment Scale with WHOQOL, Education and Economic Status in Bipolar patients

\begin{tabular}{|l|l|l|l|l|l|l|l|l|}
\hline Variable & $\begin{array}{l}\text { GSBI } \\
\text { DISC }\end{array}$ & $\begin{array}{l}\text { GSBI } \\
\text { PERM }\end{array}$ & $\begin{array}{l}\text { GSBI } \\
\text { STIM }\end{array}$ & $\begin{array}{l}\text { GSBI } \\
\text { SOBS }\end{array}$ & $\begin{array}{l}\text { GSBI } \\
\text { CONDIF }\end{array}$ & $\begin{array}{l}\text { GSBI } \\
\text { EXCIT }\end{array}$ & $\begin{array}{l}\text { GSB } \\
\text { INSEC }\end{array}$ & MAS \\
\hline WHO-QOL-BREF & -.260 & .076 & -.257 & .058 & $-.240^{*}$ & .076 & -.005 & .076 \\
\hline Education & .115 & .016 & $-.507^{* *}$ & -.043 & .195 & -052 & .038 & .160 \\
\hline Economic Status & -.098 & .003 & $-.405^{*}$ & .790 & -.063 & .038 & .152 & .056 \\
\hline
\end{tabular}

Correlation is significant at*p $<.05, * * p<0.01$ (2-tailed)

Garos Sexual Behaviour Inventory (GSBI), Discordance (DISC), Sexual obsession (SOBS), Permissiveness (PERM), Sexual stimulation (STIM), Sexual excitability (EXCIT), Sexual insecurity (INSEC), Marital Adjustment Scale (MAS), WHO Quality OfLife (WHO-QOL)

\section{DISCUSSION:}

The aim of the present study was to investigate sexual and marital adjustment in population of psychiatric patients affected by schizophrenia and bipolar disorder. It is believed that these groups are comparable when it comes to assessing quality of life and marital adjustment, both of which can have a significant impact on sexual life and behaviour. There are two important findings of this study. First is that the patients with schizophrenia had poor marital adjustment and sexual life in comparison to patients with bipolar disorder. Secondly, quality of life is poor and impaired in patients of both bipolar and schizophrenia disorder groups.

Patients with schizophrenia had inhibited sexual behaviour and lower level of sexual stimulation and performance as compared to the patients with bipolar disorder. Research shows that schizophrenic men and women are still interested in sexual relations but do not know how to bring their feelings and expressions into conscious (Jacobs \& Bobek, 2009). The findings were supported by the findings of Raja \& Azzoni (2003) and Buddeberg et al (1988). Both sexes indicated inhibition of sexual desire. The impaired ability for sexual reaction and experience was felt partly to be positive, partly negative. Another important finding of this study is that the patients with schizophrenia disorder 
had poor level of marital adjustment. This is collaborated by the finding of Beach (1966) and Thara (1997) that patients with schizophrenia had poor marital adjustment. These findings may be generalized for formulation of better treatment strategies that involve the aspect of marital adjustment and sexual behaviour.

In summary, there is little information is available regarding impact of psychiatric illness on marital adjustment and sexual behavior in bipolar and schizophrenic patients but it is very obvious that they have sever marital and sexual problems. In present study it was found that schizophrenic patients had greater problems in the adjustment with their spouse which lead their low sexual excitement. However, there are certain limitations in the current study. Study design was cross-sectional, the number of investigated persons were relatively small. A self report scale of functioning was applied, which might be influenced by current mood, i.e. depressive mood can lead to a negative bias, and manic symptoms could lead to an overestimated functioning. The study will be good if the control group is included.

\section{References:}

1. Beach, S.R.H. \& O’Leary, K.D. (1986) Treatment of depression occurring in the context of marital discord. Behaviour Therapy, $17,43-49$.

2. Garos, S., Kluck, A., Aronoff, D. (2007) Prostate cancer patients and their partners: Differences in satisfaction indices and psychological variables. Joural of Sexual Medicine, 4, 1394-1403.

3. Hickey, D., Carr, A., Dooley, B., et al (2005) Family and marital profiles of couples in which one partner has depression or anxiety. Journal of Marital and Family Therapy, 31, 171-182.

4. Jackman-Cram, S., Dobson, K. S., Martin, R. (2006) Marital problem-solving behaviour in depression and marital distress. Journal of Abnormal Psychology, 115, 380-384.

5. Jacobs, P. \& Bobek, S.C. (2009) Sexual needs of the schizophrenic client. Journal of Clinical Psychiatry, 27, 15- 20.

6. Locke, H.J. \& Wallace, K.M. (1959) Short marital adjustment scale: Their reliability and validity. Marriage and Family Living, $21,251-254$.
7. Mazza, M., Catalano, D.H.V., Nicola, M.D., et al (2010) Sexual behaviour in women with bipolar disorder. Journal of Affective Disorders, 12, 231-234.

8. Merikangas, K.R., Bromet, E.J., Spiker, D.J. (1983) Assortative Mating, Social Adjustment, and Course of Illness in Primary Affective Disorder. Archives of General Psychiatry, 40, 795-800.

9. Raja, M. \& Azzoni, A. (2003) Sexual behaviour and sexual problems among patients with severe chronic psychoses. Service of Psychiatry, Santo Spirito Hospital, Mental Health Department ASL RM E, Via Prisciano, 26, 00136 Rome, Italy.

10. Shulman, B.H. (1971) Schizophrenia and Sexual Behaviour. Medical Aspects of Human Sexuality, 5, 144-153.

11. Beach, S.R.H., Winters, K.C., Weintraub, S. (1986) Marital dissolution and distress in a psychiatric population: A longitudinal design. Behavioral Interventions, 1, 217-229.

12. Thara, R., Kamath, S, Kumar, S. (2003) Women with schizophrenia and broken marriages-doubly disadvantaged? Part I: Patient perspective. International Journal of Social Psychiatry, 49, 225232.

13. Thara, R. \& Srinivasan, T.N. (1997) Outcome of marriage in schizophrenia. Social Psychiatry and Psychiatric Epidemiology, $32,416-420$.

14. Thomas, E.J. (1997) Marital communication and decision making, New York: Free Press.

15. Weintraub, S. \& Neale, J.M. (1984) The Stony Brook High-Risk Project. Schizophrenia Bulletin, 13, 46-66.

1. *Ph.D. Scholar in Clinical Psychology, Central Institute of Psychiatry (CIP), Kanke, Ranchi, Jharkhand834006,Correspondence: priyankarai9@yahoo.co.in

2. Ph.D. Scholar in Clinical Psychology, Central Institute of Psychiatry (CIP), Kanke, Ranchi, Jharkhand834006

3. Senior Resident, Central Institute of Psychiatry (CIP), Kanke, Ranchi, Jharkhand-834006

4. MPhil (Medical and Social Psychiatry), Central Institute of Psychiatry (CIP), Kanke, Ranchi, Jharkhand834006

5. Deputy Medical Superintendent, Central Institute of Psychiatry (CIP), Kanke, Ranchi, Jharkhand-834006 